\title{
FOTO
} CINEMA

\section{La visión trágica de la vida: una intersección clave entre la filosofía de Friedrich Nietzsche y la filmografía de Woody Allen}

\section{The tragic view of life: a key intersection between the philosophy of Friedrich Nietzsche and the filmography of Woody Allen}

\author{
Daniel Acle Vicente \\ Universidad de Salamanca
}

dav@usal.es

\section{Resumen:}

La filmografía de Woody Allen ha sido ampliamente analizada desde la óptica del ámbito de la filosofía. Estas investigaciones hacen un análisis holístico en el que relacionan cuestiones amplias como cultura de masas, política, psicoanálisis, muerte o sexualidad, con el cine del director neoyorquino. En muchos de estos estudios aparece, como es lógico, la figura de Nietzsche, pues es uno de los pensadores con más repercusión en la cultura occidental a lo largo del siglo XX. Sin embargo, el carácter holístico de estos estudios impiden la realización de un análisis más exhaustivo de las posibles relaciones entre filósofo y cineasta. Este artículo pretende cubrir este vacío, centrándose en uno de los puntos clave en el pensamiento de Nietzsche y la filmografía de Allen: la visión trágica de la vida, fraguada a partir del azar-suerte y el devenir-muerte, dos conceptos clave tanto para el cineasta como para el filósofo.

\begin{abstract}
:
Woody Allen's filmography has been widely analyzed from the perspective of the field of philosophy. These investigations make a holistic analysis in which they relate broad issues such as mass culture, politics, psychoanalysis, death, or sexuality to the cinema of the New York director. In many of these studies, the figure of Nietzsche appears, as is logical, since he is one of the thinkers with the greatest impact on Western culture throughout the 2oth century. However, the holistic nature of these investigations prevents a more exhaustive analysis of the possible relationships between philosopher and filmmaker. This article aims to fill this gap by focusing on one of the key points in Nietzsche's thought and Allen's filmography: the tragic vision of life, forged from chance-luck and becoming-death, two key concepts both for the filmmaker and the philosopher.
\end{abstract}

\section{Palabras clave:}

Azar; devenir; suerte; muerte; tragedia; postmodernidad; Woody Allen; Nietzsche.

Keywords:

Chance; becoming; luck; death; tragedy; postmodernism; Woody Allen; Nietzsche. 


\section{Introducción}

Muchos son los estudios que han analizado la relación de diferentes corrientes filosóficas con el cine de Woody Allen. La mayoría incluyen la influencia del pensamiento de Nietzsche en el cine del director neoyorquino, pues ambos guardan extraordinarias simetrías. Filósofo y cineasta comparten filosofía y arte como elementos centrales de sus respectivas obras. Mientras que Allen indaga en cuestiones filosóficas a través de sus películas, abordando muchos de los grandes temas universales que siempre han inquietado al ser humano, Nietzsche, por su parte, encuentra en la obra de arte la culminación de su filosofía, evitando la construcción de un sistema filosófico en busca de certezas absolutas. La filosofía de Nietzsche es -como él mismo afirma- "perspectivista", fragmentada, hecha de retales que nos desvelan el carácter finito, vulnerable, pero, a la vez, creativo del ser humano. Muchos de los planteamientos de Nietzsche están en la base de la crisis de valores que postula la Postmodernidad: Identidad, Unidad, Verdad, Belleza o Bien; valores que también son cuestionados reiteradamente por Allen y que configuran buena parte de los cimientos sobre los que se levanta la historia cultural de Occidente (Lyotard, 2006). Aquí reside uno de los puntos de confluencia más importantes entre cineasta y filósofo, pues si el cine de Allen es la expresión vigente de la crisis de valores que abandera la Postmodernidad, la filosofía de Nietzsche representa los albores de la misma: los primeros "martillazos" -empleando la terminología nietzscheana- que anunciaban el final de los grandes sistemas filosóficos.

Este artículo de investigación se propone analizar el papel que juegan la suerte y la muerte en el cine de Allen y su relación con el azar y el devenir en la filosofía de Nietzsche, pues a partir de estos conceptos, cineasta y filósofo defienden una mirada trágica de la vida que les lleva a hacer una profunda crítica de los valores absolutos defendidos en la tradición de la cultura occidental y que encuentra claros ecos en la crisis de valores postulada por la Postmodernidad (Lyotard, 2006). 


\section{Marco teórico y metodología}

\subsection{Marco teórico}

Resulta significativo que en la autobiografía de Woody Allen, $A$ propósito de nada (Allen, 2020), así como en las biografías autorizadas por el director neoyorquino, como Conversaciones con Woody Allen (Lax, 2008) apenas se encuentren referencias a influencias de artistas, literatos o filósofos. Parece que Allen se empeña en diluir estas cuestiones y centrarse más en pequeños detalles sobre los procesos de la escritura de guion, rodaje y montaje de sus películas, así como en cuestiones de su vida sentimental. Sin embargo, las influencias son evidentes, hasta el extremo de que aparecen una y otra vez en los diálogos de sus películas: referencias explícitas al cine de Bergman, a la literatura rusa o a pensadores como Sócrates, Nietzsche o McLuhan.

Por otra parte, son muchos los estudios sobre las relaciones entre el cine de Allen y la filosofía, así lo atestiguan investigadores como Hirsch (2001), Girgus (2005) o Lee (2013), entre un largo etcétera. No obstante, estos estudios poseen un carácter holístico que relaciona grandes temas de la cultura occidental, como la religión, la muerte, la cultura de masas o las convenciones en el sexo, con corrientes filosóficas como el Existencialismo, lo que impide un análisis más exhaustivo y pormenorizado en estos estudios comparativos. La mayoría de ellos analizan algunas de las obras de Nietzsche en relación con el cine de Allen, pues es uno de los pensadores más influyentes del siglo XX, especialmente en autores del Existencialismo como Heidegger o Sartre. Sin embargo, la amplitud del objeto de estudio impide que el análisis adquiera profundidad.

Frente a la ausencia de estudios que investiguen de forma pormenorizada las relaciones entre la suerte y el azar y el devenir y la muerte en la filmografía de Allen y la filosofía de Nietzsche, se analizará el impacto de estos conceptos en sus respectivas obras y cómo a partir de los mismos se fragua la visión trágica de la vida que ambos comparten. Es precisamente en este punto donde encuentra coherencia la crítica que cineasta y filósofo realizan sobre los grandes metarrelatos (religión, metafísica y ciencia), en defensa de una 
visión de la vida que supera las verdades absolutas de los metarrelatos, una de las características esenciales del pensamiento postmoderno (Lyotard, 2006). Las únicas verdades insoslayables, tanto para Nietzsche como para Allen, son las que configuran la visión trágica de la vida: el azar-suerte y el devenir-muerte.

\subsection{Metodología}

Para desarrollar el presente artículo se han combinado dos métodos de investigación, ambos inscritos dentro del marco de los estudios cualitativos: la hermenéutica y la metodología comparada. Así, para el análisis de las películas de Allen se ha empleado la hermenéutica en la interpretación del mensaje, tanto en el nivel del diálogo como en el visual. De igual manera, para el estudio de las obras de Nietzsche, se ha recurrido a la interpretación hermenéutica. Finalmente, para la combinación interdisciplinar entre filosofía y cine se ha acudido a la metodología comparada.

La utilización de ambas metodologías no es gratuita, sino que se ajusta al objeto de estudio. Frente a otro tipo de metodologías, la hermenéutica no contempla el objeto de estudio como un ente estático ni alberga la posibilidad de aislar variables de forma absoluta, pues su objeto de estudio es mucho más poroso y complejo. Esto no quiere decir que la hermenéutica -como método de investigación- acepte un modelo de interpretación aleatorio o subjetivo, sujeto a las preferencias particulares del investigador, sino que enmarca el ejercicio hermenéutico dentro de un contexto, haciendo posible que la recepción del mensaje sea comprensible, argumentable e incluso falible.

La metodología comparada diacrónica, también conocida como método histórico-comparativo, ha servido para poner en relación los resultados obtenidos con el método hermenéutico, tanto de las lecturas de las obras de Nietzsche como de los visionados de las películas de Allen.

La hipótesis que se quiere contrastar es que tanto Nietzsche como Allen comparten una visión trágica de la vida, a partir de la cual se derivan la mayor parte de sus concomitancias. Para desarrollar esta hipótesis se 
buscará como objetivo general determinar el paralelismo existente entre el azar y el devenir en la filosofía de Nietzsche y la suerte y la muerte en la filmografía de Allen. Entre los objetivos específicos se analizarán las causas y consecuencias que hacen de estos conceptos los elementos transversales de la mirada trágica: el miedo que ambas fuerzas engendran, el impacto de lo desconocido, el bloqueo de la voluntad de actuar en los individuos, la ausencia de necesidad, la no permanencia del mundo circundante y la pérdida de control que engendran los pares azar-suerte y devenir-muerte. Pero la visión trágica de la vida no sólo posee una vertiente pesimista; como Nietzsche y Allen defienden, también implica nuevas posibilidades para la vida que deberán ser afrontadas a través de la creación de nuevos universos de sentido y significado. Bajo las fuerzas del azar-suerte y el devenir-muerte, los viejos modelos son insuficientes, por lo que habrá que crear otros nuevos.

\section{Exposición}

\subsection{La Enseñanza del sabio Sileno}

Recogida por Nietzsche en El nacimiento de la tragedia (Nietzsche, 2009, p. 64), la enseñanza del sabio Sileno ${ }^{1}$ nos muestra una visión terrible y desgarradora de la vida:

Cuenta una antigua leyenda que durante mucho tiempo el rey Midas había perseguido en el bosque, sin poder atraparlo, al sabio Sileno, acompañante de Dioniso. Cuando éste, finalmente, cayó en sus manos, el rey le preguntó qué era lo mejor y más deseable para el hombre. Tieso y envarado, el daimón guarda silencio hasta que, urgido por el rey, termina profiriendo estas palabras en medio de una estridente risa: 'iMísera estirpe efímera, hijos del azar y de la ardura!, ¿̇por qué me obligas a decirte algo, lo que te conviene no escuchar? Lo mejor de todo no está en absoluto a tu alcance, a saber, no haber

\footnotetext{
${ }^{1}$ Sobre el significado de Sileno y los silenos, Remedios Ávila Crespo apunta: “[...] "sileno" es el nombre genérico que se da a los sátiros llegados a la vejez. Los sátiros o "silenos" son genios de la Naturaleza que han sido incorporados al cortejo de Dioniso [...] Junto a los innumerables silenos, destaca el viejo Sileno, al que las ninfas confían la educación de Dionisos [...] A este sabio Sileno se refieren también Aristóteles y Apolodoro y estas referencias las recoge Nietzsche en El nacimiento de la tragedia, cuando se relata el encuentro de este sabio con Midas” (Ávila, 2000, pp 91-117).
} 
nacido, no ser, ser nada... Y, en su defecto, lo mejor para ti es... morir pronto'

(Nietzsche, 2009c, p. 64).

Esta máxima silénica queda también recogida por Allen en Match Point (2005), en la secuencia en la que Chris Wilton, tras haber asesinado a su amante embarazada y a su vecina, se encuentra con la imagen fantasmagórica de sus víctimas, y como voces de su conciencia le exigen una explicación de sus actos. Chris justifica la muerte de cada uno de los asesinatos; el del que hubiera sido su futuro hijo lo hace en los siguientes términos: "Sófocles dijo: No haber nacido nunca puede ser el mayor de los favores" (Match Point, 2005). La misma sentencia ya había sido utilizada por Allen años antes en Desmontando a Harry (Deconstructing Harry, 1997), en la secuencia en la que Harry está conversando con Cookie (una prostituta con la que acaba de tener relaciones sexuales) sobre el sinsentido de la existencia como consecuencia de la expansión y fin del universo. Harry termina diciéndole a Cookie: “¿Sabes?, debo decirte Cookie que un gran escritor llamado Sófocles dijo que seguramente era mejor no haber nacido" (Desmontando a Harry).

¿Qué significa realmente esta doctrina? La respuesta la encontramos en la descripción que del hombre hace el propio Sileno: “iMísera estirpe efímera, hijos del azar y de la ardura!” (Nietzsche, 2009, p. 64). El primer aspecto destacable es "lo efímero", es decir, el devenir y sus consecuencias, y no sólo en términos individuales, sino de la propia especie; tarde o temprano todos moriremos, incluso algún día la propia especie desaparecerá. Allen aborda la cuestión en muchas de sus películas, pero de forma paradigmática en Recuerdos (Stardust Memories, 1980), a través del personaje de Sandy Bates, un director de comedias cinematográficas que se siente turbado como consecuencia del sinsentido de la existencia y del sufrimiento humano; aspectos que todos los que le rodean parecen no percibir o que ignoran despreocupadamente con pasmosa indiferencia, ante lo cual Bates increpa:

¿Alguien leyó en la primera página del Times que la materia se desintegra? ¿Soy el único que lo ha leído? El universo gradualmente se está desintegrando. 
No quedará nada. No estoy hablando de mis películas estúpidas.

Eventualmente no habrá Beethoven ni Shakespeare ni... (Recuerdos).

Como se puede apreciar, lo que preocupa a Bates no es que desaparezca el resto del universo, sino la irremediable desaparición de todas las grandes expresiones y logros de la cultura -consecuencia de su naturaleza efímera-, como si jamás hubieran existido.

El segundo aspecto destacado por Sileno en su descripción del hombre es que es hijo del azar. Una afirmación que no sólo subraya el carácter fortuito de la existencia del hombre sino también la ausencia de finalidad en la misma; lo cual despierta una pregunta de gran calado: si la existencia carece por completo de finalidad, ¿posee en sí misma algún significado? Esta segunda cuestión, derivada de la enseñanza silénica, la encontramos abordada una y otra vez a lo largo de toda la filmografía de Allen, con una diferencia significativa respecto del planteamiento nietzscheano: mientras que Nietzsche aborda la cuestión en términos absolutos, es decir, a través del azar, Allen lo hace en términos relativos, es decir, apelando a la suerte ${ }^{2}$.

Uno de los filmes en los que Allen desarrolla de forma significativa la importancia y trascendencia de la suerte para la vida es Match Point. El filme comienza con el plano de una pelota de tenis que, a cámara lenta, pasa de un lado a otro de la pista, hasta que en un determinado momento la pelota toca la cinta y queda suspendida en la mitad, dependiendo sólo de la suerte el que caiga de un lado o de otro, es decir, que en casos como el representado -y tal y como afirma el narrador y protagonista del filme- todo depende de la suerte:

Aquél que dijo más vale tener suerte que talento, conocía la esencia de la vida. La gente tiene miedo a reconocer que gran parte de la vida depende de la suerte. Asusta pensar cuántas cosas escapan a nuestro control. En un partido

\footnotetext{
${ }^{2}$ La suerte, entendida como el azar relatado en términos relativos, se hace evidente a través de la imagen del juego de dados descrito por Nietzsche. Cuando jugamos a los dados -o a cualquier otro juego en el que el azar desempeña un papel destacado-, la combinación que se obtiene en una tirada, en sí misma carece por completo de carga de valor. Sin embargo, dicha combinación, puesta en relación con el juego -el relato- y con los jugadores -los términos relativos-, adquiere una carga de valor que expresamos con el término suerte y que, dentro del marco narrativo en que se desarrolla el juego, se expresa en términos de ganar o perder para cada jugador.
} 
hay momentos en los que la pelota golpea el borde de la red y durante una fracción de segundo puede seguir hacia delante o caer hacia atrás. Con un poco de suerte sigue hacia delante, y ganas, o no lo hace, y pierdes (Match Point).

En la enseñanza silénica devenir y azar constituyen, por tanto, el eje de coordenadas de la existencia humana: no sólo somos fruto del azar y el devenir sino que seremos engullidos por ellos. Sólo desde esta óptica tiene sentido la sentencia de Sileno: "Lo mejor de todo no está en absoluto a tu alcance, a saber, no haber nacido, no ser, ser nada... Y, en su defecto, lo mejor para ti es... morir pronto" (Nietzsche, 2009, p. 64). ¿Significa, por tanto, que la vida no tiene valor; que carece de sentido? Tanto Allen como Nietzsche dan la misma respuesta: la vida merece ser vivida, a pesar del dolor y la angustia que ésta encierra.

Uno de los abundantes ejemplos en los que Allen defiende esta tesis lo encontramos sugerido en la primera secuencia de Annie Hall (1977), en la que Alvy Singer, mirando a cámara le dice al espectador:

¿Conocen este chiste? Dos señoras de edad están en un hotel de alta montaña y dice una: iVaya, aquí la comida es realmente terrible!; y contesta la otra: Sí, y además las raciones son tan pequeñas. Pues básicamente así es como me parece la vida: llena de soledad, miseria, sufrimiento, tristeza... y, sin embargo, se acaba demasiado deprisa (Annie Hall).

El monólogo de Alvy apunta a lo que Nietzsche denominó la "experiencia dionisíaca de la vida", que consiste, por una parte, en "reconocer que todo lo que nace debe estar preparado para arrostrar el doloroso ocaso" (Nietzsche, 2009c, p. 139), y por otra, en considerar que, a pesar del sufrimiento que conlleva tanto el azar como el devenir, gracias a ellos se generan nuevas posibilidades. En definitiva, saber que la destrucción de todas las cosas deja paso a la creación de nuevas formas de vida.

Este doble aspecto, de destrucción y regeneración, es expresado por Nietzsche a través de la figura de Dioniso3, dios de lo Uno-primordial, donde

3 Dioniso es, como señala Carlos García Gual, "un dios de la vegetación del ímpetu natural, del impulso hacia una vida desbordante, del férvido brotar de las plantas y los seres 
todo es confusión, contradicción, deformidad, desorden, caos... elementos que, a pesar de ser terribles para la existencia humana, son los que la hacen posible; sólo en ellos bulle y se regenera la vida. De ahí que Nietzsche afirme: "Dioniso: es explicable únicamente por un exceso de fuerza" (Nietzsche, 2009b, p. 807). Sin embargo, en este exceso de fuerza dionisiaca, que no sólo destruye sino que también genera, no encuentra el hombre consuelo suficiente, de ahí que afirme Nietzsche: "Hasta el más valiente de nosotros sólo tiene rara vez la valentía para lo que realmente sabe..." (Nietzsche, 2009b, p. 723).

Ante el dolor de la vida, Dioniso nos proporciona la embriaguez, la música, la danza, la pasión, la orgía, el desenfreno... Pero, tras el éxtasis, el problema persiste llevándonos de nuevo al pesimismo, a la mirada que ve el absurdo de la existencia; la misma mirada que describe Nietzsche en Ecce Homo a propósito de Hamlet: “¿Se comprende a Hamlet? No la duda, la certeza es lo que vuelve loco... Pero para sentir así es necesario ser profundo, ser abismo, ser filósofo... Todos nosotros tenemos miedo de la verdad" (Nietzsche, 2015, p. 89). Es la certeza de la sabiduría silénica: que la vida es dolor, sufrimiento, angustia ante la muerte, el devenir, el azar... "Una vez que esta verdad ha sido contemplada -afirma Nietzsche- el hombre únicamente ve por doquier cuán espantoso o absurdo es el ser [...] reconoce la sabiduría del rey de los bosques, Sileno: siente asco" (Nietzsche, 2009c, p. 89).

Será preciso analizar en profundidad, a través de la filosofía de Nietzsche y de la filmografía de Allen, los elementos que configuran esa verdad insondable, ineludible, alegre y terrible, representada por Dioniso, transmitida por Sileno y que Allen aborda una y otra vez en sus más de cuarenta películas: azarsuerte y devenir-muerte en la existencia humana.

animados. Es el dios del vino y la vid; el del entusiasmo y el éxtasis, de la máscara y el tropel orgiástico. No protege la familia ni la comunidad cívica, sino el grupo de fieles que, a impulso de su inspiración, van a festejarlo en correrías y danzas extáticas por los montes. Inspira frenesí, la manía o "desvarío" que puede ser una bendición o un castigo" (García, 1995, p. $38)$. 


\subsection{Azar y suerte}

Allen, igual que Nietzsche, destaca la importancia del azar para la existencia del hombre, pero -como decíamos- lo hace en términos relativos, es decir, a través de la suerte. El azar, como tal, carece de valor, no es bueno ni malo; la suerte, por el contrario, implica el aspecto relatante y, por tanto, también valorativo. Esta idea queda perfectamente ilustrada en la primera secuencia de Match Point. Cómo veíamos, el ex jugador de tenis profesional Chris Wilton (protagonista del filme) destaca el carácter valorativo que entraña la suerte a través de la imagen de una pelota de partido (match point) que queda suspendida en la cinta de la red, cuyo resultado puede ser, como el propio personaje afirma, "ganar" o "perder", dos verbos que subrayan las consecuencias de la acción en función de su carga de valor relativa.

La idea de que la suerte rige nuestra existencia es abordada en muchas otras películas de Allen. Al inicio de Manhattan (Allen, 1979), Isaac afirma: "El talento es pura suerte"; en Recuerdos, cuando un periodista le pregunta a Sandy Bates: “¿No piensa que la base de una relación madura es el compromiso?”; Sandy responde:

Pienso que cualquier relación no está basada ni en el compromiso ni en la madurez ni en la perfección ni en nada de eso. Está basada en la suerte. Ésa es la clave. A la gente no le gusta reconocer eso porque implica una pérdida de control, pero hace falta tener suerte (Recuerdos).

El mismo planteamiento lo retoma Allen en esta misma película, en la secuencia en la que un amigo de la infancia de Sandy le está diciendo lo mucho que admira su vida -es un exitoso director de comedias-, a lo que Sandy responde:

Es una cuestión de suerte. Tuve suerte. Soy el primero en admitir mi suerte. Si no hubiera nacido en Brooklyn, si hubiera nacido en Polonia o en Berlín, hoy sería una lámpara, ¿verdad? Así que siéntete agradecido de no ser Nat Bernstein - un amigo común del barrio en que ambos crecieron que ha muerto como consecuencia de una enfermedad incurable-(Recuerdos). 
De este modo, Allen subraya la idea de que la mayoría de las cosas escapan a nuestro control, o lo que es lo mismo: hay cosas que no se pueden predecir, que son fruto de la suerte.

Nietzsche, a pesar de que no emplea el término suerte, también habla de la carga de valor que puede tener el azar para un individuo: "Juzgados desde el punto de vista de nuestra razón, los lanzamientos desafortunados de dados son, por lo general, la regla" (Nietzsche, 2009d, p. 674). Nietzsche está subrayando el carácter antropomórfico que posee toda valoración del azar. La diferencia entre el azar y la suerte estriba en que, mientras que el azar va más allá de la visión antropocéntrica del hombre, la suerte tiene como elemento nuclear el aspecto valorativo. Sin embargo, ambos conceptos están marcados por la imposibilidad de realizar predicciones fiables $\mathrm{y}$, como consecuencia, por la ausencia de control.

La cuestión de fondo que suscita el problema es de gran alcance: ¿qué significado tiene la existencia si la mayoría de las cosas suceden ciegamente (casualmente) y escapan a nuestro control? Incluso la existencia del propio hombre es producto del azar: su raciocinio, su lenguaje, su capacidad para crear universos simbólicos de significado y de sentido... Todo es fruto del azar; en palabras de Nietzsche: "El hombre se cuenta [...] entre las jugadas de azar más inesperadas y excitantes del 'gran niño' de Heráclito" (Nietzche, 2009e, p. 648). La misma tesis queda recogida, aún más explícitamente, en Aurora: “¿Que cómo ha llegado la razón al mundo? Como debe ser, de una manera insensata, por un azar" (Nietzsche, 1999, p. 121).

Igual que sucede con la "experiencia dionisíaca del mundo", el azar, como aspecto nuclear de dicha experiencia, posee una doble vertiente. Por una parte, es ciego y terrible, carente de finalidad; por otra, es inocente e inagotable. Ambos aspectos quedan recogidos en la metáfora del "gran niño" de Heráclito -a la que antes aludíamos a propósito de la existencia del hombre-, pues en ella se expresa tanto la inocencia del niño jugando como la crueldad del mismo destruyendo aquello que ha creado. El aspecto positivo del azar, la inocencia que hace posible nuevas formas, es la que reclama Zaratustra para sí mismo: “iDejad que el azar venga a mí: es inocente como 
un niño!” (Nietzsche, 2009a, p. 213). Sin embargo, el azar entendido como algo destructivo y terrible, denominado por Nietzsche como "gran azar" o "gigante azar", también es abordado por Zaratustra. En un discurso a sus discípulos les dice con dolor: "Aún luchamos, paso a paso con el gigante azar, y sobre toda la humanidad ha imperado hasta ahora el absurdo, el sinsentido" (Nietzsche, 2009a, p. 213).

El azar es el primer peldaño en la escalera de la contingencia, donde nada está guiado por necesidad y finalidad alguna, donde "las cosas suceden sin que nadie sepa decir ¿̇por qué? y ¿para qué? -Sentimos miedo ante este poderoso reino del gran desatino cósmico" (Nietzsche, 1999, p. 128). Esta es la realidad en la que vive el hombre que se asoma al abismo del "gigante azar": el miedo.

El miedo, como la consecuencia más terrible del azar para la existencia del hombre, ya lo encontrábamos sugerido por Allen en los anteriores parlamentos de Match Point y de Recuerdos: la falta de control produce miedo. El problema es abordado de nuevo en Si la cosa funciona (Whatever Works, Allen, p. 2009), en la secuencia en la que Boris Yellnikoff, un prestigioso investigador de física cuántica, le dice a Melodie a propósito de su inesperada relación sentimental:

Increíble. El factor de posibilidades en la vida es alucinante. Llegas al mundo por un hecho casual en algún lugar de Mississippi; yo, habiendo surgido de la unión de Sam y Yetta Yellnikoff, en el Bronx, décadas antes... Y por una combinación astronómica de circunstancias nuestros caminos se cruzan. Dos fugitivos en el vasto, negro, indescriptiblemente violento e indiferente universo (Si la cosa funciona).

Lo más significativo de la reflexión de Boris es que recoge, igual que Zaratustra, por una parte, la inocencia; por otra, el absurdo que implica el azar en relación con la existencia humana.

El hecho de que Allen haya escogido como profesión de Boris la física cuántica, no es gratuito. Esta especialidad de la física estudia el campo del indeterminismo a nivel subatómico (los electrones se mueven 
aleatoriamente, por lo que no es posible predecir ni medir su movimiento sin perturbar el propio sistema de medición, aspecto que, obviamente, se encuentra directamente relacionado con las implicaciones que entraña el azar). El problema del indeterminismo cuántico es abordado de nuevo en la secuencia en la que Melodie, convertida en alumna de Boris, le pregunta a su pretendiente Randy James: "¿Has oído hablar del Principio de Incertidumbre de Heisenberg? ¿Las influencias del espectador, el experimento...?" (Si la cosa funciona).

En esta misma película encontramos otro parlamento de Boris, en este caso mirando a cámara, que recoge perfectamente el significado dual del azar: "Dios, ¿̇saben las probabilidades del espermatozoide de su padre, entre miles de millones, encontrando al óvulo que los creó? No piensen en eso, les dará un ataque de pánico" (Si la cosa funciona). El ejemplo escogido por Boris expresa, por una parte, alegría por la infinidad de casualidades que han dado con cada uno de nosotros; por otra parte, angustia ante el hecho de que somos fruto del azar, de que podríamos no ser.

La relación del azar y los fines está magníficamente expresada por Nietzsche en Aurora:

[...] nosotros, sabios enanos, con nuestra voluntad y nuestros fines, somos molestados, atropellados y, a menudo, aplastados por los estúpidos, archiestúpidos gigantes, las casualidades, -pero a pesar de ello no queremos pasarnos sin la poesía turbadora de esta vecindad, pues esas fieras aparecen a menudo cuando la vida en la tela de araña de los fines nos resulta demasiado aburrida o tímida, y constituyen una sublime diversión, rompiendo con su mano, para empezar, toda la tela de araña, -sin proponérselo iestos insensatos! Pero sus toscas manos de huesos entran en la tela como si fuera aire (Nietzsche, 1999, p. 128).

De nuevo, queda expresada la doble vertiente del azar: a pesar de que aplasta y rompe nuestros fines, gracias a ello, precisamente, abre la posibilidad de otros nuevos. 


\subsection{Devenir y muerte}

El segundo aspecto destacado por Sileno en la definición del ser humano es su naturaleza "efímera": lo que no perdura, lo que deviene, lo que cambia, lo que muere. Esta idea se encuentra desarrollada en toda la obra de Nietzsche, desde el Nacimiento de la tragedia hasta Ecce homo, pero, salvo contadas excepciones, empleará el término “devenir”.

Allen, por su parte, aborda la cuestión a través del término "muerte". La diferencia de matiz entre ambos conceptos es similar a la abordada en el punto anterior entre "azar" y "suerte". Mientras que la "muerte" es antropomórfica, el "devenir" trasciende el universo simbólico del hombre, pertenece -en términos nietzscheanos- a lo "Uno-primordial”, al ámbito de lo dionisíaco. De este modo, la "muerte" es, por una parte, una de las muchas consecuencias del "devenir"; por otra parte, una interpretación en términos relativos, es decir, en relación con el modo en que los hombres otorgan valor a una de las repercusiones del paso del tiempo. Mientras que el "devenir" es un concepto que no posee carga de valor antropomórfica, la "muerte”, por el contrario, está profundamente marcada por el valor que entraña para la existencia del hombre.

El valor que otorgamos a la muerte queda perfectamente expresado en $L a$ última noche de Boris Grushenko -cuyo título original (Love and Death, 1975), recoge directamente la temática de la muerte- en la secuencia en la que Boris le pregunta a Sonia, su prima y futura mujer, si tiene miedo a morir, y ésta le responde: "Miedo no es la palabra exacta; me horroriza morir" (La última noche de Boris Grushenko). No obstante, y a pesar de que Nietzsche aborda la cuestión a través del concepto "devenir", en parte de su correspondencia transmite su preocupación por el problema más concreto de la muerte. En una carta fechada el 14 de noviembre de 1881 le dice a su amigo Overbeck: “¿qué es toda nuestra vida? Un barco que navega en el mar, ipues cualquiera sabe con certeza que un día zozobrará!” (Nietzsche, 2009d, p. 733). Este pensamiento pone de relieve el tema de la muerte desde la vida, no en términos universales, sino para cada individuo particular. 
La misma idea es abordada en Scoop (2006), cuya estructura se fragua sobre la relación existente entre vida y muerte. El filme comienza con la celebración del funeral de Strongwell, un personaje que, a pesar de estar muerto, articula todo el guion de la película desde "el más allá” (simbolizado con la imagen de la barca de Caronte, donde precisamente se cierra el filme). El hecho de que un muerto condicione las acciones de los vivos expresa metafóricamente la idea de que la muerte, como posibilidad, condiciona la propia vida.

La cuestión ya había sido abordada en Hannah y sus hermanas (Hannah and Her Sisters, 1986) a través del personaje de Mickey, en la secuencia en la que el médico le dice que cabe la posibilidad de que tenga un tumor cerebral, o lo que es lo mismo, se hace patente para el personaje la muerte como posibilidad en un futuro inminente. La consecuencia más directa para Mickey es que no sólo le cambia la vida sino también la visión que de la misma tiene: "Esta mañana yo era tan feliz ¿̇sabes?, y ahora... ahora no... no... no sé... no sé qué me ha pasado" (Hannah y sus hermanas). Gail, la compañera de trabajo con la que se está desahogando, le recuerda que eso no es cierto: "Esta mañana estabas hecho una mierda, habíamos bajado en los sondeos, los patrocinadores estaban furiosos" (Hannah y sus hermanas). Pero a Mickey la posibilidad de una muerte inminente le ha cambiado la visión de su propia vida: "No, yo era feliz, pero no me daba cuenta de que lo era" (Hannah y sus hermanas). El contraste es notable, ya que por la mañana el personaje lo veía todo en términos negativos: se quejaba de la úlcera que padece y afirmaba que el estrés en que vivía era insoportable. Sin embargo, tras saber que puede tener un tumor, toda esa angustia queda anulada ante la realidad infranqueable de la muerte.

No obstante, como el propio Mickey secundará más adelante, no hace falta tener un tumor para percibir el absurdo que representa la muerte para la vida. Cuando a Mickey le dan los resultados de las pruebas, y le dicen que no tiene un tumor cerebral, da saltos de alegría, hasta que toma conciencia de que es imposible escapar a la muerte y se vuelve a sentir arrastrado por el absurdo. La angustia le lleva a decirle a Gail (su compañera de trabajo) que 
deja el programa, exponiéndole los siguientes motivos: “¿No ves que todas las cosas carecen de sentido? iTodo! Me refiero a nuestras vidas, al programa, al mundo entero, ino tienen sentido!" (Hannah y sus hermanas). Como si el personaje estuviera suscribiendo la máxima de Sileno, le explica los motivos por los que nada tiene sentido:

Cuando salí corriendo del hospital estaba... estaba tan emocionado porque me habían dicho que no me pasaba nada que iba corriendo por la calle y, de repente, me detuve porque me di cuenta de algo: muy bien no voy a palmar hoy, estoy bien, tampoco palmaré mañana, pero tarde o temprano estoy seguro de que me tocará (Hannah y sus hermanas).

Gail, tratando de tranquilizar a Mickey y darle consuelo, le dice que la muerte es algo que nos pasará a todos, pero este argumento, lejos de tranquilizarle, hace aún más aguda la sensación de absurdo en Mickey: "Sí, pero eso a mí no me resuelve nada, porque entonces resulta que no hay nada en este mundo por lo que valga la pena vivir: tú te vas a morir, yo también, la gente se va a morir, la televisión, los patrocinadores; itodo el mundo!" (Hannah y sus hermanas).

La misma idea ya había sido expuesta en Interiores (Interiors, 1978) por el personaje de Renata en una sobremesa familiar: "No sé, decís que el pesimismo es lo que priva, pero no es difícil argüir que ante la muerte la vida pierde su significado" (Interiores). Ambos personajes representan la toma de conciencia de lo que significa la vida vista desde el máximo exponente del devenir para el hombre: la muerte.

El punto de unión en la relación muerte-vida es el miedo. Cuando Mickey va al médico para saber cuáles han sido los resultados de la prueba, está convencido de que tiene un tumor y se dice a sí mismo: "Se acabó, estoy cara a cara con la eternidad. No será dentro de unos años sino ahora. Tengo tanto miedo que no puedo ni moverme, ni hablar, ni respirar" (Hannah y sus hermanas). El mismo miedo atenaza a Harry -en Desmontando a Harryen la secuencia en que su amigo Richard fallece de un infarto en un coche en el que van, además de él y el inesperado difunto, una prostituta y su hijo 
Hilly. Harry, dirigiéndose a su hijo, le dice lo contrario de lo que siente: "No hay porqué tener miedo Hilly [...] ¿Te acuerdas que te dije que la muerte es una parte natural de la vida? iHay que asumirla!" (Desmontando a Harry); pero la exclamación “iHay que asumirla!”, en realidad es fruto del terror que siente Harry, histérico e incapaz de asumir sus propias palabras.

El miedo que Mickey y Harry experimentan frente a la muerte es extrapolado por Nietzsche a todas las cosas: "El devenir eterno y único, la absoluta indeterminabilidad de todo lo real, que constantemente actúa y deviene pero nunca es, como enseña Heráclito, es una idea terrible y sobrecogedora" (Nietzsche, 1998, p. 226). Nada permanece, nada es y, por tanto, no sólo desaparecerá cada individuo, sino que todo lo que nos rodea carece de permanencia, por lo que también desaparecerá. Este hecho genera la imposibilidad de establecer anclajes de permanencia, nos diluye en un torrente con todo lo demás; una certeza que, como hemos visto, experimentan muchos personajes de Allen.

La misma certeza es la que llevó a Anaximandro -según Nietzsche- a preguntarse a propósito de todos los seres:

¿Qué hay de valor en vuestra existencia?... Y si acaso no posee nada de valor ¿para qué existís? [...] Mirad cómo vuestra tierra se marchita, se vacían y secan los mares; lo fósiles que encontráis en lo alto de los montes os enseñan hace ya cuánto tiempo se secaron; ahora mismo, ya el fuego destruye vuestro mundo y al fin se consumirá entre el vapor y el humo. Pero una y otra vez habrá de surgir de nuevo otro mundo como éste, uno donde sólo existe lo efímero. ¿Quién será capaz de liberaros de la maldición del devenir?” (Nietzsche, 1998, p. 222).

Esta visión del devenir y de la muerte conduce a una posición pesimista de la vida: ¿qué sentido tiene la vida si todo es efímero? La certeza de que esta pregunta no posee una respuesta satisfactoria es la que deprime al pequeño Alvy, en Annie Hall, y le impide hacer sus deberes. ${ }^{4}$ La madre, que no entiende qué le sucede a su hijo, decide llevarle al médico, y cuando éste le

4 Aquí se está planteando el problema, ampliamente tratado por Nietzsche, del modo en que el pesimismo anula la voluntad. 
pregunta por qué está deprimido, el niño exclama: “iEl universo se expande!” (Annie Hall). Ante el desconcierto del médico, Alvy le explica la relación existente entre el hecho de que el universo se expanda y la depresión que sufre: "Bueno, el universo es todo, y si se expande, algún día estallará y eso será el final de todo" (Annie Hall). Este problema acompañará al personaje a lo largo de toda su vida bajo la idea de la muerte. Así se lo expresa el propio Alvy (ya adulto) a Annie: "Sí, verás, yo... yo estoy obsesionado con... con la muerte. Es un gran tema para mí y tengo una visión muy pesimista de la vida" (Annie Hall).

El pesimismo que genera la muerte es un hecho que afecta a muchos de los personajes de la filmografía de Allen, pero quizá el que mejor expresa el absurdo de la existencia, consecuencia de la certeza insoslayable de la muerte, sea Renata, la poetisa interpretada por Diane Keaton en Interiores:

Mi impotencia aconteció hace un año... mi parálisis. De repente noté que no podía seguir escribiendo, bueno, no fue de repente, empecé a notarlo el invierno pasado: insistentes pensamientos sobre la muerte iban agolpándose en mi mente. Me sobrecogía... la preocupación de mi propia mortalidad, me invadía una sensación de futilidad con respecto a mi trabajo. ¿Por qué esforzarme en seguir creando?, ¿̇con qué fin?, ¿̇on qué objeto?, ¿con qué propósito que lo justifique? La verdad, cimporta realmente que alguien lea alguno de mis poemas cuando me haya ido para siempre?, ¿va a reportarme alguna compensación? Antes yo así lo creía, pero ahora, por alguna razón, no puedo creerlo, lo considero absurdo, y no soy capaz de asumir lo que en realidad la muerte significa. Es horripilante. El pensar en ello le inhabilita a una (Interiores).

Renata, igual que el pequeño Alvy en Annie Hall, expresa la consecuencia del pesimismo ante la idea de la muerte: anula la acción del individuo -en términos nietzscheanos la "voluntad de poder". Si a Alvy el absurdo de la existencia le impedía hacer los deberes, a Renata le imposibilita escribir, le hace sentirse -como ella misma expresa- "inhabilitada". Lo que lleva a ambos personajes a la inactividad es el pesimismo que genera la ausencia de justificación moral alguna ante la imparable acción del devenir. 
Existe, no obstante, otro signo -tratado ampliamente por Allen- que anticipa el problema de la muerte y que, al igual que ésta, es consecuencia del devenir, del paso del tiempo: la vejez. Uno de los parlamentos en los que mejor se expresa esta tensión lo encontramos en Septiembre (September, 1987), en la escena en la que Diane, una mujer de avanzada edad con una vitalidad desbordante, se está probando vestidos para ir a una fiesta. Al ver su figura reflejada en el espejo reflexiona sobre el modo en que nos afecta el paso del tiempo:

¡Ay, Dios mío, cómo estoy! Tengo que retocarme todo el maquillaje. Envejecer es un infierno, sobre todo cuanto te sientes de veintiún años: todas las fuerzas que te han sostenido durante toda la vida te abandonan poco a poco. Observas tu cara en el espejo y... y notas que te falta algo; entonces te das cuenta de que es el futuro (Septiembre).

El futuro en la vejez, tal como nos muestra el personaje de Diane, expresa la acción del devenir, la pérdida del pasado. Este hecho es el que hace que Nietzsche sea particularmente crítico con el exceso de pasado, pues impide la posibilidad de un presente que mire al futuro con nuevas posibilidades. El exceso de pasado mata la vida, aniquila la inocencia del presente. No es, por tanto, gratuita la imagen del niño -empleada por Nietzsche- "que juega en confiada inconsciencia entre las cercas del pasado y el futuro sin tener aún que rechazar nada de su pasado" (Nietzsche, 2009g, p. 328). Pero esa inocencia del niño, viviendo su presente, desaparecerá con la aparición de la palabra "fue", a través de la conciencia del pasado que expresa el devenir de la vida:

hasta que un buen día la muerte, finalmente, traiga el ansiado olvido, sustrayendo la posibilidad del presente y del existir y presentando el sello de ese conocimiento que enuncia que la existencia es un ininterrumpido haber sido, algo que vive negándose, consumiéndose y contradiciéndose continuamente (Nietzsche, 2009g, p. 328).

La misma contradicción es expresada por Allen en Comedia sexual de una noche de verano (A Midsummer Night's Sex Comedy, 1982), en la escena en la que Ariel y Andrew, apoyándose en el recuerdo de una vieja historia de 
amor que tuvieron en el pasado, descubren que su amor es irrecuperable, que el tiempo pasa y transforma a las personas, que vivir del pasado es imposible: "Caray, el tiempo pasa. Antes de que te des cuenta se te cae un poco de pelo, cualquier ruido te molesta... supongo que es que sencillamente cambiamos, nos convertimos en otras personas" -concluye Ariel (Comedia sexual de una noche de verano).

La máxima que se deriva de los efectos del devenir es que no podemos vivir del pasado, pues hacerlo constituye una ilusión que nos enjaula en un presente contradictorio y absurdo, cargado de frustración. En Hannah y sus hermanas, Mickey reflexiona sobre el absurdo de evitar lo inevitable, el intento de retrasar los efectos de la acción del devenir en el cuerpo (donde mejor se perciben los efectos del paso del tiempo): "Y toda esa gente, haciendo footing, intentando demorar la inevitable decadencia de su cuerpo. Pobres, me dan lástima, los sacrificios que hacen las personas con sus bicis, sus ejercicios..." (Hannah y sus hermanas).

La idea de que el exceso de pasado no es saludable para la vida, o el hecho aún más radical de vivir bajo la ilusión de permanencia en el pasado, apunta a una visión positiva del devenir. Igual que sucedía con el azar, tanto Nietzsche como Allen ven en el devenir un aspecto positivo, pues representa la posibilidad de lo nuevo, lo diferente, lo sorprendente... Por tanto, el hecho de que todo esté atravesado por la temporalidad, no significa que el tiempo sólo destruya, pues esa acción de destruir abre paso a la posibilidad de todo lo nuevo.

Para Nietzsche el único filósofo que ha sido capaz de expresar teóricamente esta realidad en toda su hondura, sin subterfugios, fue Heráclito:

[...] en cuya cercanía -dice Nietzsche- siento más calor y me encuentro de mejor humor que en ningún otro lugar. La afirmación del fluir y del aniquilar, que es lo decisivo en la filosofía dionisiaca, el decir sí a la antítesis y a la guerra, el devenir, el rechazo radical incluso del concepto mismo de "ser" -en esto tengo que reconocer, en cualquier circunstancia, lo más afín a mí entre lo que hasta ahora se ha pensado (Nietzsche, 2009b, p. 79). 
¿A qué se refiere Nietzsche con "el rechazo radical del concepto mismo de 'ser'”? Obviamente está criticando la ilusión metafísica de la permanencia, de lo que es unidad. Para Nietzsche la esencia dionisiaca consiste en un eterno fluir donde nada permanece. De ahí la crítica que hace al exceso de pasado. En Mas allá del bien y del mal, Nietzsche expresa su crítica a la ilusión de permanencia y verdad a la que tiende el pensamiento:

¡Ay! ¿Qué será de vosotros, oh pensamientos míos, una vez escritos y pintados? No hace mucho tiempo aún erais tan jaspeados, tan jóvenes, tan maliciosos, tan llenos de aromas picantes y secretos, que me hacíais estornudar y reír. ¿Y ahora? Ya os habéis despojado de vuestra novedad, y algunos de vosotros ya estáis prestos, me lo temo, a cambiaros en verdades: iTal aire inmortal, dolorosamente verídico y enojoso tenéis! (Nietzsche, 2009f, p. 575).

La crítica a la inmortalidad del pensamiento, descrita aquí por Nietzsche, es llevada al individuo por Allen en Manhattan (Manhattan, 1979), a través del personaje de Tracy, una adolescente que censura las operaciones de estética como remedio para combatir los signos de la vejez, o lo que es lo mismo, anclarse en el pasado: “¿Por qué no envejecen naturalmente sin hacerse todas esas porquerías?” (Manhattan).

La realidad es dinámica en todas sus vertientes, en el caso del ser humano lo es desde el pensamiento hasta el cuerpo, pasando incluso por las relaciones sentimentales, tal y como le dice Alvy a Annie en Annie Hall: "Las relaciones son como un tiburón, tiene que moverse hacia adelante constantemente o se muere" (Annie Hall). La misma idea queda patente en Manhattan, de nuevo a través del personaje de Tracy: "Quizá las personas no fueron hechas para tener una sola relación profunda. Tal vez deberíamos tener una serie de relaciones con eslabones distintos..." (Manhattan). Tracy está planteando la posibilidad de que el amor, como la vida, fluye, de que nada permanece, pero nos aferramos a la ilusión de permanencia porque su ausencia representa la fragilidad, el fino hilo sobre el que nos hallamos suspendidos -como dice Mickey en Hannah y sus hermanas-, porque en última instancia genera miedo. La misma fragilidad que enriquece, gracias a que nos arrebata parte 
del pasado - planteada por Tracy-, es descrita por Nietzsche a propósito del corazón: “[...] quizá más incierto, más delicado, más frágil, más roto, pero más lleno de esperanzas que no tienen aún nombre, lleno de un deseo y de un flujo nuevos, lleno de una repulsa y de reflujo nuevos..." (Nietzsche, 2009f, p. $573)$.

\section{Conclusiones}

La relación entre el "azar" y lo "efímero", reunidos en la descripción silénica del hombre que Nietzsche recoge en el Nacimiento de la tragedia, poseen, como se ha visto, una doble vertiente: la destrucción y su condición inherente para lo nuevo. Mientras que el primer aspecto conduce al pesimismo, el segundo posibilita una visión menos descarnada. Una dualidad que es precisamente la que constituye la visión trágica de la vida, en la que cada uno tiene la oportunidad de crear universos de sentido para la vida sin negar su fondo paradójico.

Tras el estudio comparativo realizado podemos afirmar que la hipótesis propuesta se ve confirmada, tal como demuestra el análisis de los objetivos que la acompañan, cuyo cometido ha sido determinar la importancia del azar-suerte y del devenir-muerte como elementos clave en la formación de la mirada trágica que tanto Allen como Nietzsche comparten. Los objetivos específicos, por su parte, nos han desvelado que bajo el azar-suerte las cosas carecen de necesidad y, por tanto, de control; unido al devenir-muerte, que todo lo cambia, genera miedo en la condición humana hasta el extremo de paralizar a la voluntad de actuar. Hasta aquí la perspectiva pesimista que generan estas fuerzas, pero más allá, tanto Nietzsche como Allen, defienden una postura positiva, pues si el azar-suerte y el devenir-muerte rompe con toda explicación estable de la vida, son ellas precisamente las que abren la posibilidad de nuevas formas de afrontar la vida.

A partir de esta mirada trágica se entienden mucho mejor las críticas que tanto Allen como Nietzsche hacen a los grandes metarrelatos, relatos 
universales, como la ciencia, la religión, la metafísica o la alta cultura, que han negado el azar-suerte y el devenir-muerte como los elementos insoslayables de la vida. Estos grandes metarrelatos, que fraguan los cimientos de la cultura occidental desde la antigua Grecia, son puestos en entredicho no sólo por Nietzsche y por Allen, sino que es uno de los signos distintivos del pensamiento postmoderno (Lyotard, 2006).

La aportación de este estudio a la literatura científica sobre el tema tratado, es que Allen y Nietzsche no hacen una mera crítica a la religión, la metafísica o la ciencia, como modelos morales que niegan la vida, sino que tras estas críticas hay un paradigma ético, apoyado en su la visión trágica de la vida. $\mathrm{Si}$ el azar-suerte y el devenir muerte son las únicas verdades inquebrantables, carece de sentido defender valores absolutos. Tampoco hacen una crítica absoluta y nihilista a todos los valores; se trata de abolir los valores absolutos, para que cada individuo sea capaz de darse a sí mismo sus propios valores.

\section{Referencias bibliográficas}

Allen W. (2020). A propósito de nada. Trad. E. Hojman. Madrid: Alianza Editorial.

Ávila C. R. (2000). Aquella excéntrica fisonomía de sileno. Agonismo y piedad en la reflexión de Nietzsche en torno a Grecia. Logos. Anales del Seminario de Metafísica, 2, pp. 91-117. Servicio de Publicaciones, Universidad Complutense: Madrid.

García Gual. C. (1995). Introducción a la mitología griega. Madrid: Alianza.

Girgus, S. (2005). El cine de Woody Allen. Trad. F. López. Madrid: Akal.

Hirsch, F. (2001). Love, Sex, Death, and the Meanning of Live: The Films of Woody Allen. New York: Da Capo Press.

Lax, E. (2008). Conversaciones con Woody Allen. Trad. A. Leiva. Barcelona: Lumen.

Lee, S. (2013). Woody Allen's Angst: Philosophical Commentaries on His Serious Films. North Carolina: McFarland.

Lyotard, J. F. (1987). La condición postmoderna. Trad. M. Antolín. Madrid: Cátedra. 
Nietzsche, F. (2009a). Así habló Zaratustra. Un libro para todos y para nadie. (Vol. 2). Trad. J. R. Hernández. Madrid: Gredos.

Nietzsche, F. (2009b). El crepúsculo de los ídolos o Cómo se filosofa con el martillo. (Vol. 2). Trad. J. Mardomingo. Madrid: Gredos.

Nietzsche, F. (2009c). El nacimiento de la tragedia. (Vol. 1). Trad. G. Cano. Madrid: Gredos.

Nietzsche, F. (2009d). La ciencia jovial. (Vol. 1). Trad. G. Cano. Madrid: Gredos.

Nietzsche, F. (2009e). La genealogía de la moral. Un escrito polémico. (Vol. 2). Trad. J. Mardomingo. Madrid: Gredos.

Nietzsche, F. (2009f). Más allá del bien y del mal. Preludio para una filosofía del futuro. (Vol. 2). Trad. C. Vergara. Madrid: Gredos.

Nietzsche, F. (2009g). Sobre la utilidad y el perjuicio de la historia para la vida. (Vol. 1). Trad. G. Cano. Madrid: Gredos.

Nietzsche, F. (1995). Aurora. Trad. M. de Juan. Barcelona: Alba Editorial.

Nietzsche, F. (2015). Ecce Homo. Trad. A. Sánchez Pascual. Madrid: Alianza Editorial.

Nietzsche, F. (1998). La filosofía en la época trágica de los griegos. Trad. L. F. Moreno. Madrid: Valdemar. 